\title{
Micellar Solubilization in the Formulation Development of Poorly Soluble Naproxen
}

\author{
Parvataneni Durga Maheswari ${ }^{1}$, Devraj Rambhau ${ }^{1 *}$ and Mangamoori Lakshmi Narasu ${ }^{2}$
}

${ }^{1}$ Natco Research Centre, Natco Pharma Limited, Sanathnagar, Hyderabad 500 018, Andhra Pradesh, India

2Jawaharlal Nehru Technological University Hyderabad, Hyderabad 500 085, Andhra Pradesh, India

\begin{abstract}
The aim of this study was to improve the dissolution rate of naproxen using micellar solubilization technology. Cloud point temperature of the nonionic surfactants has been used as the basis for the solubility study because there is better entrapment of the drug into the surfactant micelle at this temperature. Naproxen was solubilized in polysorbate 80 micelles at cloud point temperature; lactose was dissolved in micellar dispersion and the dispersion was directly spray-dried to obtain microparticles, which was subsequently converted into tablets using suitable excipients. The spray-dried particles were characterized and in-vitro dissolution studies were carried out. Spray-dried naproxen powder and tablets made out of it by direct compression method, have exhibited superior dissolution rate over controls in all media employed irrespective of $\mathrm{pH}$ conditions. Therefore, it is believed that the better dissolution characteristics conferred by the micellar solubilization of naproxen and rapid wetting of microparticles.
\end{abstract}

Keywords: Solubility; Surfactant; Micellar solubilization; Cloud point temperature; Spray-drying; Microparticles; Dissolution

\section{Introduction}

There is a general consensus in the pharmaceutical industry that poorly water-soluble drug candidates are becoming more prevalent [1]. When water-solubility is less than $1 \mu \mathrm{g} / \mathrm{mL}$, which is often the case for contemporary drug candidates, the bioavailability from conventional tablet formulations may be unacceptable. There are a number of formulation strategies that could be used to improve the bioavailability of poorly soluble drugs either by increasing the dissolution rate or by maintaining the drug in solution in the gastrointestinal tract.

The various formulation strategies for the solubility enhancement of poorly soluble drug, reported in various research articles include complexation with cyclodextrins [2,3], polymeric nanoarchitecture [4], self emulsifying drug delivery system [5], pH adjustment and salt formation [6], micronization, use of cosolvents, emulsions and microemulsion, nano suspensions, micellar solubilization and solid dispersion [7].

The Cloud Point Temperature (CPT) is the lower consolute temperature (LCST), above which cloudiness suddenly appears on heating the aqueous solutions of surfactants containing polyethylene oxide (PEO) chains. The diameter of these micelles rapidly rises at temperatures above the LCST, due to hydrophobic interactions that result in the aggregation of the micelles. This effect of temperature on size was shown to be reversible, since the micellar architecture was maintained after lowering the temperature below the LCST. Nonionic surfactants with PEO chains as the hydrophilic moiety are used frequently in pharmaceutical formulations. The clouding behavior of non-ionic block co-polymeric surfactant in water is an interesting feature influencing their practical usefulness [7].

The attractive interaction between PEO chains at elevated temperature in water may account for clouding behavior. At this temperature the surfactant solution separate into two immiscible phases that are surfactant rich phase containing most of surfactants and a water phase having surfactant with concentration only around its critical micelle concentration [8].

Naproxen was chosen as a model poorly soluble drug for this work. Naproxen is effective in reducing pain like rheumatoid arthritis, osteoarthritis, juvenile arthritis and acute gout without any serious cardiovascular or respiratory side effects [9].
Rapid onset of action is desirable to provide fast relief in the treatment of pain due to the abovementioned diseases. Therefore, it is necessary to enhance the aqueous solubility and dissolution rate of naproxen to obtain faster onset of action, minimize the variability in absorption.

Research works put forwarded many techniques for the solubility enhancement of naproxen. Several earlier workers focused on the solubility enhancement of poorly soluble naproxen by hydrotropy technique using $\mathrm{N}, \mathrm{N}$-dimethyl urea, sodium benzoate, niacinamide, ibuprofen sodium as the hydroptropy agents [10-13]. William et al. investigated the process of preparing nanoparticulate system for delivery of naproxen comprising a premix of the crystalline drug substance and a surface modifier, subjecting the premix to mechanical means to reduce the particle size of the drug substance, the mechanical means producing shear, impact, cavitation and attrition [14]. Arlie et al. investigated for solubilizing delivery systems and method of manufacture by blending of the active agent/surfactant combinations using selected processing conditions to at least partially place a eutectic of the combinations into intimate contact with particles of the active [15]. Jae-Hwan et al. developed a solvent system of hardly soluble naproxen with improved dissolution rate thus enhance bioavailability by improving the disintegration degree and dissolution ratio of naproxen [16]. Chen Feng-jing and Patel Manesh studied about compositions and methods for improved delivery of ionizable hydrophobic therapeutic agents like naproxen [17]. Wang et al. studied pseudo-stationary phases with SDS as an anionic surfactant, tween 20 as a nonionic surfactant or SDStween 20 mixed micelles were examined to control the separation and migration behavior of four acidic compounds similar in structure, including ketoprofen, naproxen, sulindac and indometacin in micellar electrokinetic capillary chromatography [18].

*Corresponding author: Devraj Rambhau, Department of Novel Drug Delivery System, Natco Research Centre, B-13, Industrial Estate, Sanathnagar, Hyderabad 500 018, Andhra Pradesh, India, Tel: (+91) 9849995721; Fax: (+91) 040-23710578; E-mail: drambhau@yahoo.co.in

Received February 12, 2013; Accepted May 15, 2013; Published May 20, 2013

Citation: Maheswari PD, Rambhau D, Narasu ML (2013) Micellar Solubilization in the Formulation Development of Poorly Soluble Naproxen. Pharmaceut Reg Affairs 2: 108. doi:10.4172/2167-7689.1000108

Copyright: ( 2013 Maheswari PD, et al. This is an open-access article distributed under the terms of the Creative Commons Attribution License, which permits unrestricted use, distribution, and reproduction in any medium, provided the original author and source are credited. 
Paudel Amrit et al. reported that there is an increase in the solubility of naproxen with the use of polyvinyl pyrrolidone of different molecular weights [19]. Liquisolid technique was also employed to improve the dissolution profile of naproxen by Tiong and Elkordy [20]. The evaluation of HP- $\beta-C D$ as solubilizing agent for naproxen by complexation technique was investigated by Yuan-Yuan et al. [21]. Zhan Guo-ping and Pan Dao-li investigated on the solubility enhancement of naproxen with $\beta-\mathrm{CD}$ as solubilizing agent [22]. Wongmekiat et al. revealed that co-grinding of naproxen with $\mathrm{CD}$ results in, not only the formation of drug nanoparticles but also the solubilization of the drug by inclusion complex formation with $\mathrm{CD}$ in aqueous media [23]. Cirri et al. studied the simultaneous effect of cyclodextrins complexation, $\mathrm{pH}$ and hydrophilic polymers on naproxen solubilization and revealed that the combined strategy of $\mathrm{pH}$ control and polymer addition to the cyclodextrins complexing medium can be successfully exploited to improve naproxen solubilization and reduce the amount of cyclodextrin needed [24]. Mura et al. investigated the combined effect of hydroxypropyl- $\beta$-cyclodextrin and different amino acids (L-lysine, LYS; L-valine, VAL; L-iso-leucine, LEU; and L-arginine, ARG) on the solubility of naproxen and revealed that arginine was the most effective amino acid in improving drug solubility and the only one showed a synergistic effect when used in combination with hydroxypropyl- $\beta$ cyclodextrin [25]. Velaz et al. revealed the effect of PEG 4000 on the dissolution rate of naproxen by developing its solid dispersions with PEG 4000 by fusion and solvent evaporation method [26].

Mura et al. studied solid dispersions of naproxen in polyethylene glycol 4000, 6000, and 20000, aiming for an improvement in the drug dissolution characteristics, were prepared by both the solvent and melting methods. The increase in naproxen dissolution rate from its binary systems with polyethylene glycol was attributed to several factors such as improved wettability, local solubilization, and drug particle size reduction [27]. Lee and Lee revealed that inclusion complexes of poorly water soluble naproxen with 2-Hydroxypropyl$\beta$-Cyclodextrin were useful to increase solubility and dissolution rate, resulting in enhancement of bioavailability [28]. Bettinetti and Mura investigated for the dissolution properties of solid dispersions (coevaporates and colyophylized) and physical mixtures of naproxen with different molecular weight of PVP [29]. The thermal behavior and dissolution properties of naproxen in combinations with chemically modified $\beta$-cyclodextrins have been investigated by Bettinetti et al. and revealed the formation of amorphous products with higher dissolution rates [30].

The interaction of naproxen with $\beta$-cyclodextrins in ground mixture and its effect on the dissolution rate was studied by Celebi and Erden and concluded the enhancement of the dissolution rate in the ground mixture with cyclodextrin [31]. Bettinetti et al. studied the interaction of naproxen with polyvinylpyrrolidone in aqueous solution and in the solid state and concluded that freezedried solid dispersion of naproxen containing $40-60 \%$ by wt. poly(vinylpyrrolidone) of mean molecular weight 25,000 provided the highest dissolution enhancement, relative to crystalline drug, of 4.5fold in water [32]. Nurham and Nevin revealed that $\beta$-Cyclodextrin enhanced the solubility and dissolution rate of naproxen better than intact naproxen. A solid naproxen- $\beta$-cyclodextrin (1:2) complex was prepared by freeze-drying neutralization and by ground mixture [33]. Yiyun and Jiepin studied the Solubilization of non-steroidal antiinflammatory drugs in the presence of tween series surfactants and results showed that the solubility of NSAIDs in the tween solutions was approximately proportional to tween concentration; the ability of tween series surfactants to solubilize NSAIDs in the present study was Tween-80>Tween-60>Tween-40>Tween-20 [34]. Thermal behavior and dissolution properties of naproxen_from binary and ternary solid dispersions were studied by Mura et al. [35].

Briefly, naproxen is directly added to surfactant solution maintained at CPT and a water-soluble inert carrier material like lactose or mannitol was added to micellar solubilized naproxen aqueous system and the solution was spray-dried to obtain a solid product. The solid product was converted to a tablet formulation using directly compressible diluents and other excipients. Naproxen and surfactant-solubilized spray-dried naproxen were evaluated for particle size distribution, flow ability, compressibility, dissolution rate and stability. The tablet formulation, made with spray-dried naproxen was evaluated as per compendial parameters and finally the rate of dissolution was assessed in different dissolution media.

\section{Materials and Methods}

\section{Materials}

Naproxen (NAP) with $99.67 \%$ purity was purchased from Divis Laboratories Limited. The surfactants like Polysorbate 80 (P80) and Polysorbate 20 (P20) were purchased from Merck Limited and Solutol HS 15 (ST15) and Cremophor RH 40 (CRH40) were kindly supplied by BASF, Germany. The coating material Opadry was kindly supplied by Colorcon. All other ingredients used were of pharmaceutical grade and solvents were of high pressure liquid chromatography grade. Water used in this study was purified by a Milli-Q synthesis A10 system (Millipore, Billerica, MA) unless otherwise mentioned.

\section{Methods}

Cloud point studies: The cloud point temperatures (CPT) were obtained by placing the test tubes each containing a surfactant solution of $1,5,15$ and $25 \%$ (w/v) of P20, P80, CRH40 and ST15, into a temperature-controlled bath. The sample solutions were heated to a temperature where cloudy appearance was visualized. Typically it was observed that the solution turns slightly blue and translucent, then completely turbid within one degree. The temperature at the first sign of the turbidness was taken as the CPT. On cooling, the phase separated surfactant redissolved immediately.

Micellar solubilization: Micellar solubilization of NAP was performed by employing cloud point technique, wherein drug was solubilized in surfactant solution at CPT. Aqueous surfactant solutions of $1,5,15$ and $25 \%(\mathrm{w} / \mathrm{v})$ of P20, P80, CRH40 and ST15 were used as solubilizing media. The surfactant solutions $(5 \mathrm{~mL})$ were taken in centrifuge tubes, heated in a water bath up to CPT and excess amount of NAP was added under stirring, solutions were cooled to room temperature (RT) and the solubility of NAP was estimated. NAP solubility in all the surfactant solutions was also determined at RT. Both the lots (RT and CPT) were kept under shaking at RT using orbital shaker for 24 hours to attain equilibrium. The aliquots of these samples were centrifuged, filtered through a $0.45 \mu \mathrm{m}$ nylon membrane filter (Millipore Millex-HN), suitably diluted with methanol and were subjected to UV spectrophotometric analysis of NAP at 332 nm (Shimadzu 1800). Solubility studies were performed in triplicate. The saturation solubility of NAP in water without surfactant was determined at RT and at temperatures corresponding to CPT (at maximum $90^{\circ} \mathrm{C}$ ) of various surfactants.

Spray-drying of micellar solubilized NAP: Among the various surfactant solutions employed in the solubility study, P80 (1\% w/v) which allowed maximum solubility of NAP $(0.73 \mathrm{mg} / \mathrm{mL})$ was chosen 
as the product candidate for further studies. For the purpose of spraydrying the required quantity $(3 \% \mathrm{w} / \mathrm{v})$ of lactose monohydrate was dissolved in the surfactant solution containing dissolved NAP and the solution was subjected to spray-drying using mini buchi spray dryer (B-190, Buchi Labortechnik AG, Switzerland). Similar procedure was followed for the preparation of placebo with the same concentration of P80 and lactose monohydrate. The composition of aqueous micellar solution for spray-drying.

The micellar solution was pumped through an atomizer device that produced fine droplets in the main drying chamber with continuous stirring. The following conditions were used during spray-drying: spraying air flow, $600 \mathrm{~L} / \mathrm{h}$; solution feed rate, $7.5 \mathrm{~g} / \mathrm{min}$; nozzle size, $0.5 \mathrm{~mm}$. The inlet temperature was set at $120^{\circ} \mathrm{C}$; pump setting, $40 \%$; aspiration setting, $100 \%$. These conditions resulted in an outlet temperature of $75-76^{\circ} \mathrm{C}$. The same procedure was followed for spraydrying of placebo micellar solution. The resultant powders of spraydried naproxen (SDN) and spray-dried placebo (SDP) were collected and stored in a dessicator at ambient temperature.

Characterization of NAP, SDN and SDP: The spray-dried powders were evaluated based on yield, angle of repose, bulk density (BD) and tap density (TD) of the samples. The flow properties have been evaluated by the measurement of angle of repose, whereas, Carr's Index values and Hausner's ratio were calculated from BD and TD data for NAP, SDN and SDP, as a measure of the compressibility aspect of the powders. The moisture content in NAP, SDN and SDP were analyzed by Karl Fischer (K.F) titration method. The porosity was determined by liquid displacement method to evaluate the impact of combined use of micellar solubilization and spray-drying on the morphological characteristics.

Naproxen content in SDN was analyzed by dispersing $50 \mathrm{mg}$ of SDN in $5 \mathrm{~mL}$ of methanol in order to extract NAP. The suspension was kept in an ultrasonic bath for 15 minutes and then was centrifuged for 15 minutes at $2500 \mathrm{rpm}$ and filtered through a $0.45 \mu \mathrm{m}$ nylon membrane filter. After suitable dilution, the content of NAP was determined UV spectrophotometrically at $332 \mathrm{~nm}$ using a standard plot $(5-30 \mathrm{mcg} / \mathrm{mL})$ with a correlation coefficient $\left(\mathrm{r}^{2}\right)$ of 0.9991 .

Particle size and size distribution (PSD) of NAP and SDN: The particle size of NAP and SDN was determined by laser light diffraction with a wet sampling system. The equipment consisted of a Malvern particle size analyzer [Model: Hydro 2000 SM (A)]. $100 \mathrm{mg}$ of sample was dispersed in $20 \mathrm{~mL}$ of liquid paraffin and the diameters reported were calculated using volume distribution (six sets of measurements) with the evaluation of data by software current version 5.22 .

Size analysis of micellar dispersions: The mean size and size distribution of micellar dispersions was determined by photon correlation spectroscopy using zetasizer ZS90 (Malvern instruments, Malvern, UK). The micelle dispersion was diluted to a suitable concentration with filtered Milli-Q water. Analysis was performed at $25^{\circ} \mathrm{C}$ with an angle of detection of $90^{\circ}$. The mean size $( \pm$ S.D) was directly obtained from the instrument.

\section{Scanning electron microscopy (SEM)}

The morphology of samples was observed using a SU1510 scanning electron microscope (Hitachi, Japan). Powder samples were fixed on an aluminium stub with conductive double-sided carbon tape, and observed under SEM using low vaccum mode (VP-SEM). The specimens were scanned with an electron beam of $15 \mathrm{kV}$ acceleration potential and photomicrographs were taken at $1000 \mathrm{X}$ magnification for NAP and 4000X magnification for SDN.

\section{Fourier transform infrared spectroscopy (FTIR)}

The infrared spectra of NAP, SDN and SDP were recorded on a Bruker FTIR spectrometer (Model Tensor 27). The pellet preparation was carried out using about $4 \mathrm{mg}$ of the powder compressed with 100 $\mathrm{mg}$ of potassium bromide. The scans were obtained at a resolution of 2 $\mathrm{cm}^{-1}$ from 4000 to $500 \mathrm{~cm}^{-1}$.

\section{Differential scanning calorimetry (DSC)}

Thermal analysis was carried out with a DSC instrument (Mettler Toledo, DSC823 $)$. About $10 \mathrm{mg}$ of samples were weighed into a nonhermetically sealed aluminum pan and heated from $40-280^{\circ} \mathrm{C}$ at a heating rate of $10^{\circ} \mathrm{C} / \mathrm{min}$ under a nitrogen flow rate of $80 \mathrm{~mL} / \mathrm{min}$.

\section{$\mathrm{X}$-ray powder diffractometry (XRPD)}

XRPD was performed with an X-ray diffraction system (Panalytical, X'Pert PRO diffractometer) using the detector pixel. The powders were exposed to $\mathrm{Cu}-\mathrm{K}_{\alpha}$ radiation source at $45 \mathrm{kV}$ and $40 \mathrm{~mA}$. Diffraction patterns were obtained in $2 \theta$ at a range of $0-70^{\circ}$ using $0.02^{\circ}$ step size and $10 \%$ min scan speed. The measurement was done with the application of X'Pert Highscore.

\section{Formulation of tablets}

SDN was blended with spray-dried lactose (SDL) granules (as a diluent) and lubricated with magnesium stearate. Slugs of $0.2 \mathrm{~g}$ from the lubricated blend were produced using flat-faced tooling $15.4 \times 6.85$ $\mathrm{mm}$ in diameter on a 12-station tablet press MT S/F (Rimek MinipressII). The slugs were crushed in a multimill using $2 \mathrm{~mm}$ screen (Anchor Mark Pvt. Ltd; Model MML) to obtain granules. The resulting material was passed through a vibro sifter (Anchor Mark Pvt. Ltd; Model VSF $12 ; 300 \mathrm{~mm}$ dia) using a $1.68 \mathrm{~mm}$ sieve. The resultant material was again slugged with the same procedure to obtain the desired flow properties to the granules. Thus, obtained granules were again lubricated with magnesium stearate and compressed into tablets (SDN+SDL) with $15.4 \times 6.85 \mathrm{~mm}$ shallow concave punches. The external addition of the optimized amount of spray-dried lactose during slugging imparted suitable hardness and aesthetic appearance for the tablets from the spray-dried powders. Because of the tendency to pick up the moisture by the spray-dried powders blending, slugging, milling, lubrication and compression was performed at temperature between $21^{\circ} \mathrm{C}$ and $25^{\circ} \mathrm{C}$ at relative humidity $(\mathrm{RH})$ between $30-50 \%$. The same procedure was followed for SDP+SDL+NAP and SDL+NAP tablets.

To aid in keeping the tablet intact during handling, to provide more elegance and to prevent moisture pick up, a thin film coating was applied by opadry white until weight gain attained $2.5 \%$ over the tablet weight. Coating dispersion was prepared by dispersing opadry white in Milli-Q water under constant stirring for 15-20 minutes by using propeller stirrer (Remi) followed by filtration through 100-mesh nylon cloth. Coating of tablets was done using pan coating apparatus pharma R\&D coater (Ideal Cures Pvt. Ltd.) fitted with a 6" pan with baffles on the interior walls and using a $1 \mathrm{~mm}$ spraying gun and a 3 inches gun to bed distance. $200 \mathrm{~g}$ of tablets were placed in the pan which was pre heated at $45^{\circ} \mathrm{C}$ temperature for 5-10 minutes. Process parameters were adjusted as follows: spray rate $(3 \mathrm{~g} / \mathrm{min})$, inlet air temperature $\left(70^{\circ} \mathrm{C}\right)$, atomizing air pressure $\left(1.5 \mathrm{~kg} / \mathrm{cm}^{2}\right)$, pan speed $(35 \mathrm{rpm})$, and percentage solid content $(9.1 \%)$. After finishing of the coating, tablets were kept in the pan at $40^{\circ} \mathrm{C}$ and rotated at $5 \mathrm{rpm}$ for curing. The coated tablets were stored in tightly closed glass container and evaluated for various properties such as weight variation, thickness, friability, hardn ess and disintegration time. The content uniformity and dissolution employing various media was assessed by UV spectrophotometric method. 
Citation: Maheswari PD, Rambhau D, Narasu ML (2013) Micellar Solubilization in the Formulation Development of Poorly Soluble Naproxen. Pharmaceut Reg Affairs 2: 108. doi:10.4172/2167-7689.1000108

Page 4 of 12

\section{In-vitro release studies}

Powders: The in-vitro drug release study from SDN powder, NAP (mesh 40/60), SDP+NAP and NAP+P80 (equivalent amount of surfactant present in SDN added to the dissolution media), equivalent to $5 \mathrm{mg}$ NAP were carried out using an 8-station USP 23 dissolution testing apparatus (Electrolab, India, model TDT-08L). The dissolution tests were carried out at $37^{\circ} \mathrm{C}( \pm 0.5)$ using $300 \mathrm{~mL}$ of $0.1 \mathrm{~N} \mathrm{HCl}, \mathrm{pH} 4.5$ $( \pm 0.1)$ acetate buffer, pH $6.0( \pm 0.1)$ phosphate buffer, demineralised water $(\mathrm{DM}), \mathrm{pH} 6.8( \pm 0.1)$ phosphate buffer and $0.1 \mathrm{M} \mathrm{pH} 7.4$ $( \pm 0.1)$ phosphate buffer at $30 \mathrm{rpm}$ employing U.S. food and drug administration (FDA) recommended dissolution method, using USP apparatus II. At predetermined time intervals $5 \mathrm{~mL}$ of samples were withdrawn, filtered through $0.45 \mu \mathrm{m}$ nylon membrane filter (Millipore Millex-HN) and analyzed spectrophotometrically at $332 \mathrm{~nm}, \mathrm{r}^{2}=0.9998$ for $0.1 \mathrm{~N} \mathrm{HCl}, \mathrm{r}^{2}=0.9997$ for $\mathrm{pH} 4.5$ acetate buffer, $\mathrm{r}^{2}=0.9999$ for $\mathrm{pH}$ 6.0 phosphate buffer, $\mathrm{r}^{2}=0.9998$ for DM Water, $\mathrm{r}^{2}=1.0000$ for $\mathrm{pH} 6.5$ phosphate buffer, $\mathrm{r}^{2}=0.9997$ for $\mathrm{pH} 6.8$ phosphate buffer and $\mathrm{r}^{2}=0.9996$ for $0.1 \mathrm{M} \mathrm{pH} 7.4$ phosphate buffer. Naprosyn (MKT), $375 \mathrm{mg}$ tablets were crushed (mesh 40/60), and equivalent weight (containing $5 \mathrm{mg}$ of naproxen) was taken with the calculated assay for the dissolution study in the abovementioned dissolution media as a mark of comparative drug release study. At each time of withdrawal, $5 \mathrm{~mL}$ of fresh corresponding medium was replaced into the dissolution flask. The cumulative amount of drug release was calculated and plotted versus time.

Tablets: Dissolution of immediate release tablets made with $\mathrm{SDN}+\mathrm{SDL}, \mathrm{SDP}+\mathrm{SDL}+\mathrm{NAP}, \mathrm{SDL}+\mathrm{NAP}, \mathrm{SDL}+\mathrm{NAP}+\mathrm{P} 80$ (equivalent amount of surfactant present in SDN added in the dissolution media) equivalent to $5 \mathrm{mg} \mathrm{NAP}$, were carried out in all media with different $\mathrm{pH}$ similar to conditions like powders. Dissolution study of marketed tablets of Naprosyn (MKT I), $375 \mathrm{mg}$ were performed in all the above buffers at $30 \mathrm{rpm}$ using USP apparatus II.

\section{Statistical analysis}

The dissolution profile obtained with powders and tablets were statistically analyzed for difference factor $\left(f_{1}\right)$ and similarity factor $\left(f_{2}\right)$. The results were compared using fit factors [36], adopted by the FDA guidance for dissolution testing.

\section{Stability study}

Stability studies were performed according to international conference on harmonisation (ICH) guidelines [37]. The SDN powder and SDN+SDL tablets were stored in high density polyethylene containers and were exposed for stability study at $25 \pm 2^{\circ} \mathrm{C} / 60 \pm 5 \%$ $\mathrm{RH}$ and $40 \pm 2^{\circ} \mathrm{C} / 75 \pm 5 \% \mathrm{RH}$ in the respective stability chambers (Thermolab, Mumbai). Moisture content, assay and dissolution were studied as stability comparative aspect after 3 and 6 months of the respective condition. The dissolution was carried out in $0.1 \mathrm{M}$ phosphate buffer $\mathrm{pH} 7.4$ as per USP recommended dissolution.

\section{Results and Discussion}

\section{Cloud point studies}

With increase in surfactant concentration, CPT of the surfactants decreased (Table 1). ST15 showed lower CPTs compared to other three surfactants. P20 with lower alkyl chain $\left(\mathrm{C}_{12}\right)$ exhibited higher CPT than P80 with a higher alkyl chain length. The effect of concentration on CPT was insignificant for P20 and CRH40, where as this effect was more pronounced in case of ST15.

\section{Naproxen solubility}

Broadly, with increase in surfactant concentration, aqueous solubility of NAP increased (Table 1) with all surfactants. At a concentration of $10 \mathrm{mg} / \mathrm{mL}(1 \% \mathrm{w} / \mathrm{v}), \mathrm{P} 80$ has imparted a better solubility of NAP around $0.73 \mathrm{mg} / \mathrm{mL}$ than any other employed surfactants. Thus, the solubilization capacity of P80 was about 0.073 mg NAP per $\mathrm{mg}(73 \mathrm{mg} / \mathrm{g})$ of surfactant, as against $0.05 \mathrm{mg} / \mathrm{mg}(50$ $\mathrm{mg} / \mathrm{g}$ ) achieved by other three surfactants. However, the solubility and surfactant concentration did not exhibit a linear relation over the range of concentrations employed. Thus, the solubilization capacity ( $\mathrm{SC}=$ number of $\mathrm{mg}$ of drug solubilized by number of $\mathrm{mg}$ of surfactant) for a given surfactant did not remain constant, but decreased beyond a certain surfactant concentration (Figure 1).

In general, the amount of drug solubilized in a micellar system increases with increase in temperature. To test this, we have studied solubility of NAP at RT and CPT. The percent solubility enhancement (SE) of NAP at CPT over the RT was calculated by the following formula.

\begin{tabular}{|c|c|c|c|c|c|c|}
\hline \multirow[t]{2}{*}{ Surfactant code } & \multirow[t]{2}{*}{ Surfactant $(\mathrm{mg} / \mathrm{mL})$} & \multirow[t]{2}{*}{$\mathrm{CPT}\left({ }^{\circ} \mathrm{C}\right)$} & \multicolumn{2}{|c|}{ Solubility* (mg/mL) } & \multicolumn{2}{|c|}{ Solubilization capacity (mg/g of surfactant) } \\
\hline & & & RT & CPT & RT & CPT \\
\hline \multirow[t]{4}{*}{ P20 } & 10 & $98.5 \pm 0.5$ & $0.269 \pm 0.061$ & $0.453 \pm 0.064$ & 27 & 45 \\
\hline & 50 & $98.2 \pm 0.8$ & $0.701 \pm 0.054$ & $1.127 \pm 0.182$ & 14 & 23 \\
\hline & 150 & $98.0 \pm 0.7$ & $3.303 \pm 0.05$ & $4.837 \pm 1.058$ & 22 & 32 \\
\hline & 250 & $96.8 \pm 0.5$ & $10.821 \pm 0.144$ & $11.167 \pm 0.309$ & 43 & 45 \\
\hline \multirow[t]{4}{*}{ P80 } & 10 & $92.4 \pm 0.6$ & $0.625 \pm 0.052$ & $0.729 \pm 0.181$ & 63 & 73 \\
\hline & 50 & $89.0 \pm 0.7$ & $2.591 \pm 0.051$ & $2.67 \pm 0.625$ & 52 & 53 \\
\hline & 150 & $86.2 \pm 0.5$ & $8.908 \pm 0.067$ & $8.938 \pm 0.27$ & 59 & 60 \\
\hline & 250 & $84.6 \pm 0.6$ & $12.249 \pm 0.154$ & $13.783 \pm 0.284$ & 49 & 55 \\
\hline \multirow[t]{4}{*}{$\mathrm{CRH} 40$} & 10 & $92.6 \pm 0.6$ & $0.384 \pm 0.022$ & $0.496 \pm 0.022$ & 38 & 50 \\
\hline & 50 & $91.4 \pm 0.6$ & $1.061 \pm 0.049$ & $1.264 \pm 0.029$ & 21 & 25 \\
\hline & 150 & $90.0 \pm 0.7$ & $3.605 \pm 0.133$ & $5.108 \pm 0.017$ & 24 & 34 \\
\hline & 250 & $89.4 \pm 0.6$ & $6.478 \pm 0.142$ & $7.597 \pm 0.028$ & 26 & 30 \\
\hline \multirow[t]{4}{*}{ ST15 } & 10 & $80.0 \pm 0.7$ & $0.068 \pm 0.022$ & $0.422 \pm 0.415$ & 7 & 42 \\
\hline & 50 & $77.4 \pm 0.6$ & $0.182 \pm 0.039$ & $0.687 \pm 0.038$ & 4 & 14 \\
\hline & 150 & $74.0 \pm 0.7$ & $0.969 \pm 0.116$ & $1.119 \pm 0.006$ & 6 & 7 \\
\hline & 250 & $72.4 \pm 0.6$ & $1.119 \pm 0.028$ & $1.523 \pm 0.118$ & 4 & 6 \\
\hline
\end{tabular}

Note: Each value represents mean \pm SD $\left(n=5 ;{ }^{*} n=3\right) ; R T$ : Room Temperature; CPT: Cloud Point Temperature.

Table 1: Effect of concentration of nonionic surfactants on CPT and solubility of naproxen. 


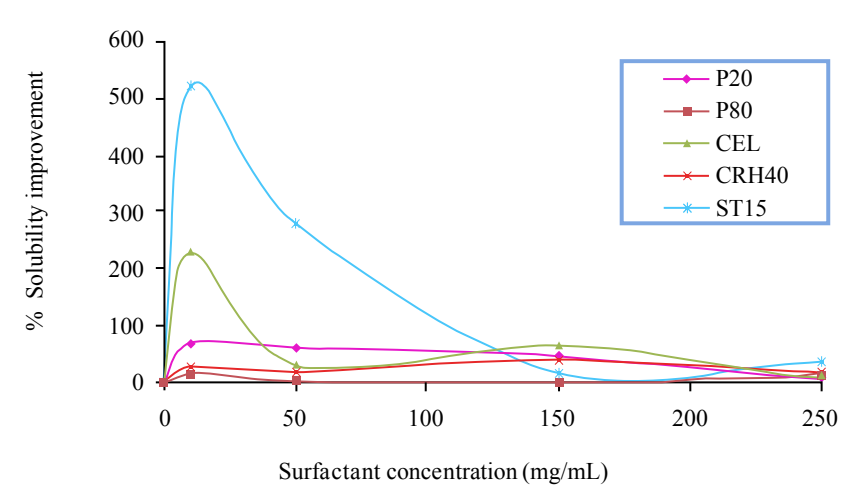

Figure 1: Solubility improvement of naproxen at cloud point temperature over room temperature with different concentrations of nonionic surfactants.

$$
\% \mathrm{SE}_{\mathrm{CPT}}=\left[\left(\mathrm{S}_{\mathrm{CPT}}-\mathrm{S}_{\mathrm{RT}}\right) / \mathrm{S}_{\mathrm{RT}}\right] \times 100
$$

Where, $\% \mathrm{SE}_{\mathrm{CPT}}=\%$ Solubility enhancement at $\mathrm{CPT} ; \mathrm{S}_{\mathrm{CPT}}=$ solubility at $\mathrm{CPT}$ and $\mathrm{S}_{\mathrm{RT}}=$ solubility at $\mathrm{RT}$ for a given surfactant concentration. The $\% \mathrm{SE}_{\mathrm{CPT}}$ versus surfactant concentration $(\mathrm{mg} / \mathrm{mL})$ is plotted in (Figure 1) and observed that at CPT there was a considerable enhancement in solubility of NAP at lower surfactant concentration whereas, with increase in surfactant concentration the \% SE declined. From $50 \mathrm{mg} /$ $\mathrm{mL}$ and above surfactant concentration, the CPT effect on solubility enhancement was relatively less than the lower concentrations of the respective surfactant.

\section{Spray-drying of P80 solubilized NAP}

During spray-drying, micellar system and drug were exposed to high temperatures $\left(80-90^{\circ} \mathrm{C}\right)$ which are almost nearer to CPT. Since, P80 system rendered highest solubility of NAP $(0.73 \mathrm{mg} / \mathrm{mL})$ at $1 \% \mathrm{w} / \mathrm{v}$ concentration and thus P80 was selected for preparation of micellar system followed by spray-drying process. The optimized weight ratio of drug: surfactant:lactose was kept at 0.35:5:15 for SDN. The similar ratio was maintained for placebo system i.e. SDP which was devoid of drug (Table 2). The drug loading in SDN was between 96.0$98.0 \%$. The powder recovery from the drier was $75-85 \%$ and the SDN had only around $1 \%$ moisture. The details of flow and compression characteristics of NAP, SDN and SDP are recorded in table 3. The SDN and SDP showed comparable micromeritic, flow and compressible properties.

\section{Evaluation of spray-dried powders}

PSD of NAP and SDN: The particle size distribution data (Table 4) of NAP and SDN reveal that SDN has higher size $(53.331 \mu \mathrm{m})$ than NAP $(34.221 \mu \mathrm{m})$. This is obviously due to formation of NAP-Lactose hybrid particles, where in the original NAP particles/micelles are trapped into lactose micro-aggregates.

\section{Size analysis of micellar dispersions}

The size of micellar dispersions are shown in table 5. The original P80 micelle size was around $9-10 \mathrm{~nm}$ and has not increased substantially inspite of the surface interaction with NAP molecules. Upon dissolving lactose into colloidal solution, the size marginally increased to 11.38 nm.

\section{SEM analysis}

SEM picture showed no definite shape for NAP particles. The crystalline structure of NAP particles is revealed by figure $2 \mathrm{~A}$. The NAP and lactose composite microparticles are spherical (Figure 2B) with a relatively smooth surface.

\section{FTIR-spectra}

The $-\mathrm{CH}$ out of plane bending vibrations due to $\mathrm{CH}=\mathrm{CH}$ at 673.56 $\mathrm{cm}^{-1}$ has also been recognized in naproxen spray-dried powder at $676.39 \mathrm{~cm}^{-1}$. The $\mathrm{C}=\mathrm{O}$ stretching vibrations due to non conjugated $-\mathrm{C}=\mathrm{O}$ obtained at $1728.46 \mathrm{~cm}^{-1}$ for $\mathrm{SDN}$ at $1734.95 \mathrm{~cm}^{-1}$. The peaks (Figure 3) at $2867.58 \mathrm{~cm}^{-1}$ for SDN due to $-\mathrm{CH}$ stretching vibrations $\left(\mathrm{C}-\mathrm{CH}_{3}\right)$ is corresponding to the peaks at $2841.26 \mathrm{~cm}^{-1}$ for NAP. The broad bands obtained for $-\mathrm{OH}$ are present at $3362.77 \mathrm{~cm}^{-1}$ in SDN (Figure 3).

\section{DSC studies}

The DSC thermogram comparison between naproxen API and SDN shows the presence of extremely low concentration of naproxen in the spray-dried Powder for which very negligible peak has appeared in the SDN. The small endothermic peak of NAP from thermogram indicates that NAP is distributed homogenously in within SDN.

In the thermogram of NAP (Figure 4), the sharp endothermic peak at $153.88^{\circ} \mathrm{C}$, with $-118.21 \mathrm{~J} / \mathrm{gm}$ enthalpy was observed. The corresponding small peak for NAP in SDN appears at $152.82^{\circ} \mathrm{C}$, which may be due to the entrapment of the drug into the surfactant micelles. Due to the absence of NAP in SDP, the above-mentioned peak is absent in the thermogram of SDP. The endothermic peak for lactose monohydrate is obtained at $224.18^{\circ} \mathrm{C}$ for SDP and is absent in the thermogram of NAP. The small endothermic peak of NAP from thermogram of SDN indicates that NAP is distributed homogenously in within spray-dried powder.

\section{XRPD studies}

The XRPD pattern of NAP, SDN and SDP has been summarized in figure 5, crystallinity for naproxen API is found to be more than the SDN and SDP. The relative intensity of all the peaks of naproxen API is more than that of the peaks at corresponding position in the diffractogram of naproxen spray-dried powder. The diffractogram reveals that the solubility enhancement of the spray-dried powder may be due to the decrease in the crystallinity of the spray-dried powder. The peaks due to lactose monohydrate have also been revealed in the SDN and SDP.

The appearance of new peak indicates the presence of new solid crystalline phase in case of SDN. The diffractrogram of SDP also reveals the same crystalline pattern as that of SDN which suggests that lactose monohydrate and spray-drying procedure together contributed to this change of form. However, the crystallinity of SDN is less due to the amorphosization of lactose during spray-drying.

\section{Dissolution profiles of powders}

SDN powder showed significant higher dissolution (Figure 6) in $0.1 \mathrm{~N} \mathrm{HCl}, \mathrm{pH} 4.5$ acetate buffer, DM water and $\mathrm{pH} 6.0$ phosphate buffer when compared to controls $\left(\mathrm{f}_{1}>10\right.$ and $\left.\mathrm{f}_{2}<50\right)$. However, in $\mathrm{pH}$ 6.8 and $0.1 \mathrm{M} \mathrm{pH} 7.4$ phosphate buffer NAP+P80 $\left(\mathrm{f}_{1}=2.2\right.$ and $\left.\mathrm{f}_{2}=79.6\right)$ and marketed product $\left(f_{1}=3.9\right.$ and $\left.f_{2}=59.2\right)$ showed nearly comparable dissolution profile to that of SDN respectively. In contrast, complete dissolution could not be achieved by NAP within $30 \mathrm{~min}$ as such in any

\begin{tabular}{|c|c|c|c|c|}
\hline $\begin{array}{c}\text { Formulation } \\
\text { code }\end{array}$ & \multicolumn{3}{|c|}{ Components (g) } & \\
\hline & Naproxen & Surfactant (P80) & $\begin{array}{c}\text { Lactose } \\
\text { monohydrate }\end{array}$ & Water up to \\
\hline SDN & 0.7 & 10 & 30 & $1000 \mathrm{~mL}$ \\
\hline SDP & 0 & 10 & 30 & $1000 \mathrm{~mL}$ \\
\hline
\end{tabular}

Table 2: Composition of aqueous micellar system for spray-drying. 
Citation: Maheswari PD, Rambhau D, Narasu ML (2013) Micellar Solubilization in the Formulation Development of Poorly Soluble Naproxen. Pharmaceut Reg Affairs 2: 108. doi:10.4172/2167-7689.1000108

Page 6 of 12

\begin{tabular}{|c|c|c|c|c|c|c|c|}
\hline Code & $B D(g / m L)$ & TD (g/mL) & $\mathrm{Cl}(\%)$ & HR & $\operatorname{AR}\left({ }^{\circ}\right)$ & MC $(\%$ w/w $)$ & $\mathbf{P} \%$ \\
\hline NAP & $0.35 \pm 0.01$ & $0.51 \pm 0.02$ & $31.70 \pm 0.46$ & $1.46 \pm 0.01$ & $51.91 \pm 0.99$ & $0.142 \pm 0.01$ & $72.47 \pm 0.39$ \\
\hline SDN & $0.31 \pm 0.003$ & $0.40 \pm 0.003$ & $22.55 \pm 0.86$ & $1.29 \pm 0.01$ & $44.67 \pm 0.29$ & $1.55 \pm 0.016$ & $99.03 \pm 0.342$ \\
\hline SDP & $0.28 \pm 0.01$ & $0.41 \pm 0.02$ & $32.28 \pm 4.15$ & $1.48 \pm 0.1$ & $41.83 \pm 1.37$ & $1.15 \pm 0.052$ & $97.33 \pm 0.298$ \\
\hline
\end{tabular}

Note: Each point represents mean \pm SD ( $n=3)$; BD: Bulk Density; TD: Tapped Density; Cl: Carr's Index; HR: Hausner's Ratio; AR: Angle of Repose; MC: Moisture Content; P: Porosity.

Table 3: Characterization of naproxen, spray-dried naproxen and spray-dried placebo.

\begin{tabular}{|c|c|c|c|c|}
\hline Code & \multicolumn{3}{|c|}{ Particle size \pm SD $(\mu m)$} \\
\hline & Average size & $d(0.1)$ & $d(0.5)$ & $31.741 \pm 0.078$ \\
\hline NAP & $34.22 \pm 0.09$ & $10.496 \pm 0.042$ & $38.271 \pm 0.368$ \\
\hline
\end{tabular}

Note: $d$ is defined as diameter, where $d(0.1), d(0.5)$ and $d(0.9)$ are the diameters at $10 \%, 50 \%$ and $90 \%$ cumulative volume, respectively.

Table 4: Particle size distribution of naproxen and spray-dried naproxen, $(n=6)$.

\begin{tabular}{|c|c|c|c|c|c|}
\hline \multirow[t]{2}{*}{ Product } & \multicolumn{3}{|c|}{ Weight of components in $\mathrm{g} / 100 \mathrm{~mL}$ of dispersion } & \multirow[t]{2}{*}{ Average size $(\mathrm{nm}) \pm \mathrm{SD}$} & \multirow[t]{2}{*}{ PI } \\
\hline & NAP & P80 & LAC & & \\
\hline PMD & 0 & 1 & 0 & $9.85 \pm 0.14$ & 0.18 \\
\hline $\mathrm{PMD}+\mathrm{L}$ & 0 & 1 & 3 & $11.60 \pm 0.23$ & 0.28 \\
\hline $\mathrm{PMD}+\mathrm{N}$ & 0.07 & 1 & 0 & $9.89 \pm 0.11$ & 0.15 \\
\hline $\mathrm{PMD}+\mathrm{N}+\mathrm{L}^{*}$ & 0.07 & 1 & 3 & $11.38 \pm 0.58$ & 0.24 \\
\hline $\mathrm{PMD}+\mathrm{N}+\mathrm{L}^{* *}$ & 0.07 & 1 & 3 & $10.14 \pm 0.16$ & 0.13 \\
\hline
\end{tabular}

Notes: Each point represents mean \pm SD $(n=3)$; PMD, polysorbate 80 micelle dispersion; N and NAP, naproxen; L and LAC, lactose monohydrate; PI, polydispersity index. "Micellar dispersion before spray-drying; "*Reconstituted micellar dispersion from spray-dried NAP (SDN).

Table 5: Characterization of micellar dispersions of polysorbate 80 and interaction of naproxen/lactose with micelles.

of the media employed. Among various media, the NAP dissolution rate was slowest in $\mathrm{pH} 1.2$ buffer medium. Irrespective of the media used, a rank order relation between NAP products and their dissolution was evident.

\section{$\mathrm{NAP}<(\mathrm{SDP}+\mathrm{NAP})<(\mathrm{NAP}+\mathrm{P} 80)<\mathrm{SDN}$}

\section{Tablets}

Using SDN and directly compressible vehicle such as SDL, tablets containing $5 \mathrm{mg}$ of NAP (SDN+SDL) were prepared (Table 6). In a similar manner, tablets of SDP+SDL+NAP and SDL+NAP were prepared. These three products were characterized employing compendial methods (Table 7). The weight variation, content uniformity, thickness were comparable for three formulations. A slight higher hardness and lower friability was observed with SDN+SDL tablets, compared to other two. The SDN+SDL tablets showed significantly higher disintegration time than the other two control tablets. The lower friability and higher disintegration time noted with SDN+SDL tablets is consistent with higher hardness noticed with these tablets.

\section{Dissolution of tablets}

The rate and extent of release of NAP from SDN+SDL tablets (Figure 7) was much superior to the commercial product of NAP and as well as SDL+NAP tablets employed in the study $\left(\mathrm{f}_{1}>10\right.$ and $\left.\mathrm{f}_{2}<50\right)$. In all the dissolution media the release from SDN+SDL tablets was higher than other products. However, in DM water (SDL+NAP+P80 tablets: $\mathrm{f}_{1}=9.8$ and $\left.\mathrm{f}_{2}=56.6\right), \mathrm{pH} 4.5$ acetate buffer (SDL+NAP+P80 tablets: $\mathrm{f}_{1}=9.6$ and $\left.\mathrm{f}_{2}=58.7\right)$ and $\mathrm{pH} 6.8$ phosphate buffer $(\mathrm{SDP}+\mathrm{SDL}+\mathrm{NAP}$ tablets: $f_{1}=13.4$ and $\left.f_{2}=53.3\right)$, the release of NAP from SDL+NAP+P80 and SDP+SDL+NAP tablets showed nearly comparable dissolution profile to that of SDN+SDL tablets. The poor dissolution of NAP from marketed tablets in contrast, the superior performance of SDN+SDL tablets in all the media is noteworthy. The $\mathrm{pH}$ independent higher rate of dissolution of SDN+SDL tablets is interesting and it reveals the potential of microparticle entrapped micelles in the development of NAP tablets.

\section{Stability studies}

The stability data reported in table 8 shows that there is no substantial change in the appearance, assay and dissolution profile on storage at accelerated conditions. The superior dissolution performance of SDN+SDL tablets in $0.1 \mathrm{M} \mathrm{pH} 7.4$ phosphate buffer was maintained even after exposure of these tablets to accelerated conditions for 6 months. The test is showed $100 \%$ release within 30 minutes. However, the moisture content was found to increase with passage of time and increase in humidity of the storage condition.

\section{Discussion}

Several earlier workers focused on developing microparticles of poorly soluble drugs using spray-drying technique. Hydrophilic surfactants [38,39] and polymers [40-42] were used in these studies to improve dissolution and oral bioavailability of poorly soluble drugs. Maghsoodi. M studied on naproxen microparticles containing Eudragit L100 and Aerosil by the emulsion solvent diffusion method in order to avoid local gastrointestinal irritation and conformed the gastrointestinal resistance with drug release studies [43]. Our approach was different from these workers as we have prepared the microparticles of naproxen with the combined use of hydrophilic surfactants and lactose monohydrate in order to improve wetting of microparticles because of hydrophilic surfactants. We have completely solubilized NAP in an aqueous system using micellar solubilization method. To this aqueous system soluble carrier like lactose was added and solution was spray-dried to obtain a solid product, which was subsequently converted into a tablet formulation.

Scanning electron microscopy showed that both SDN and SDP consisted of relatively discrete, spherical particles which were morphologically different from the NAP. Spray-drying resulted in spherical microparticles of lactose, in which micelles containing NAP 
Citation: Maheswari PD, Rambhau D, Narasu ML (2013) Micellar Solubilization in the Formulation Development of Poorly Soluble Naproxen. Pharmaceut Reg Affairs 2: 108. doi:10.4172/2167-7689.1000108

Page 7 of 12
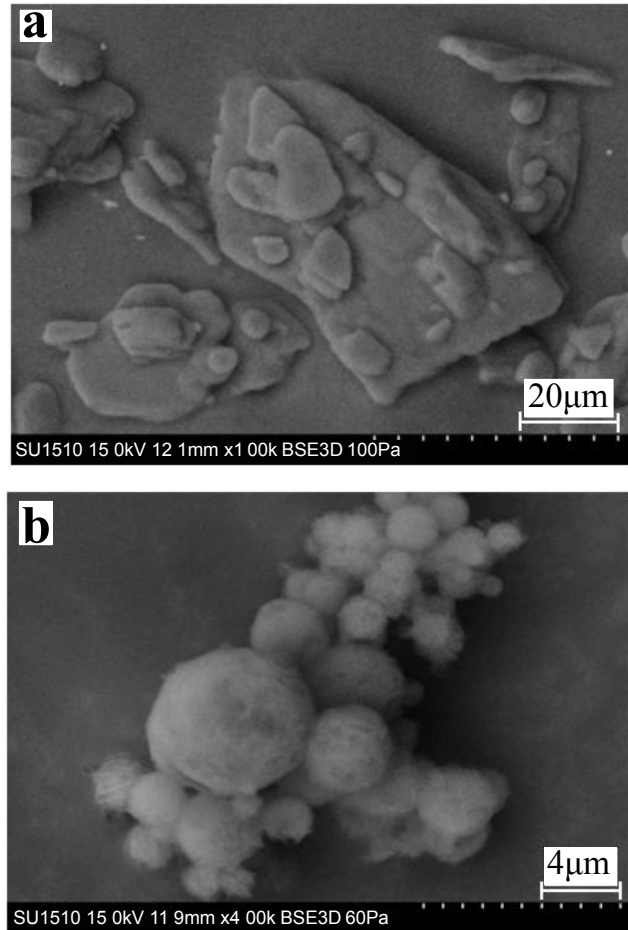

Figure 2: SEM of (NAP) naproxen powder (a) and (SDN) spray-dried naproxen (b).

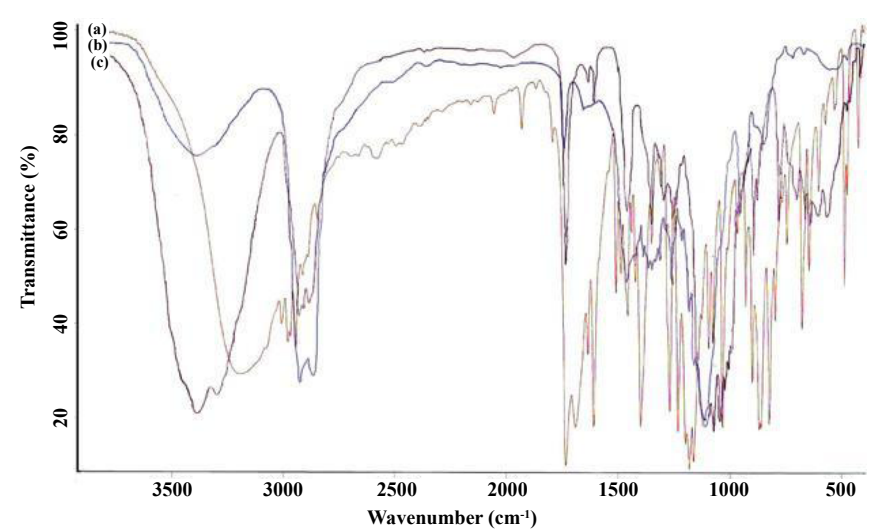

Figure 3: FTIR spectra of (a) naproxen, (b) spray-dried naproxen and (c) spray-dried placebo.

were entrapped. The original T80 micelle size was around $9.85 \mathrm{~nm}$ and has not increased even due to interaction with NAP molecules whereas, the incorporation of lactose molecules resulted in marginal increase in the micelle size. These interactions between micelle, NAP and lactose have facilitated the formation of composite microparticle firmly holding drug entrapped micelles. The micellar dispersion obtained on reconstitution of SDV with water exhibited a size of $10.14 \mathrm{~nm}$, which is approximately equivalent to the size of original NAP entrapped micelle $(9.89 \mathrm{~nm})$.

The improved dissolution and complete release of NAP from SDN and SDN+SDL tablets at high $\mathrm{pH}$ medium may be because of micellar solubilization of NAP and rapid wetting of microparticles. The improved wetting is because of amorphous lactose and presence of P80 at particle/medium interface. Because of capillary force, once water penetrates microparticles, NAP entrapped micelles will be solvated and continuously released into the medium. The SDN particles exhibited a faster dissolution rate than the controls. Interestingly, like SDN the enhanced aqueous solubility of NAP was retained by SDN+SDL tablets even after several steps of tablet processing, particularly primary and secondary compactions. Thus, SDN tablets rendered higher rate of dissolution than controls and commercial tablets of NAP.

Surfactants play an important role in the formulation development of poorly soluble active ingredients in context to their aqueous solubility. The solubility of poorly soluble compound is quiet low unless the $\mathrm{cmc}$ is achieved by the surfactant concentration. As the surfactant

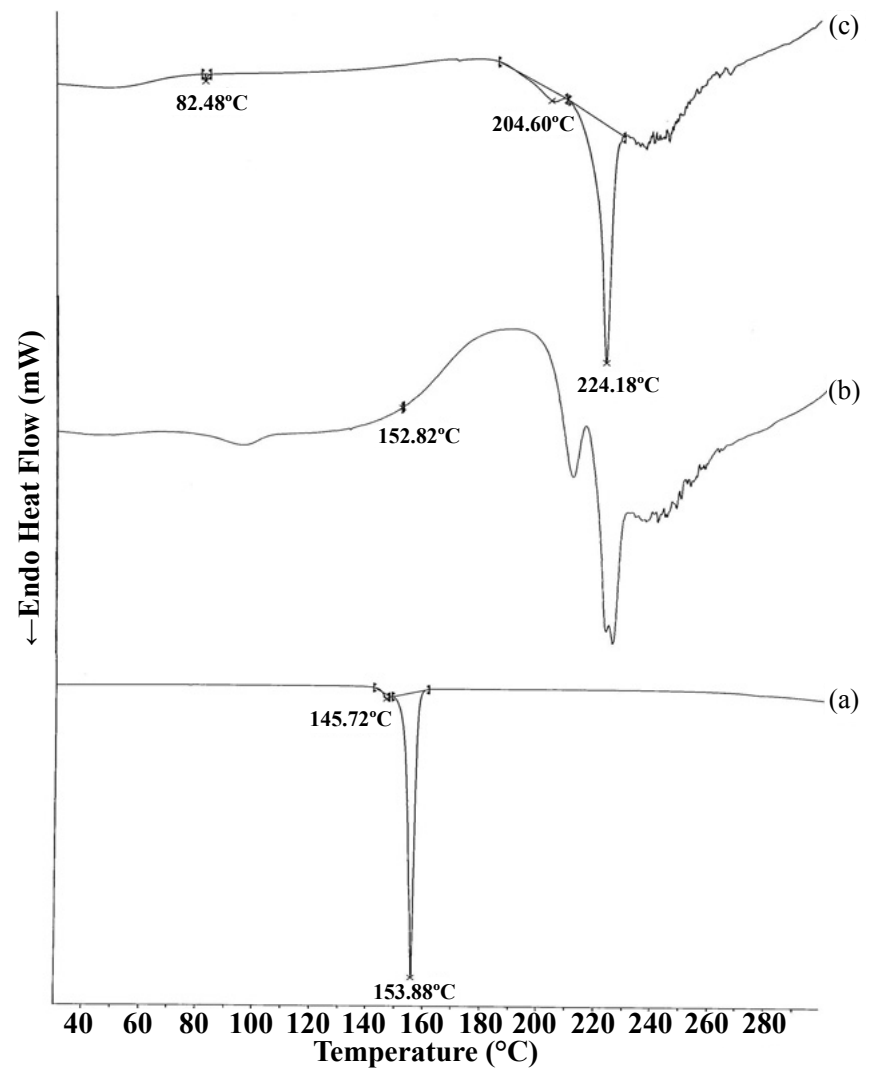

Figure 4: DSC thermogram showing (a) naproxen, (b) spray-dried naproxen and (c) spray-dried placebo.

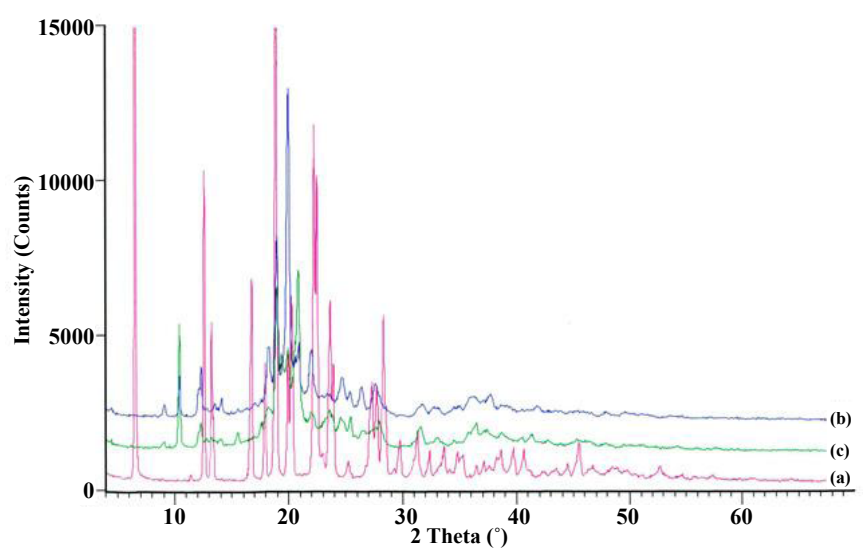

Figure 5: X- ray powder diffraction pattern of (a) naproxen, (b) spray-dried naproxen and (c) spray-dried placebo. 

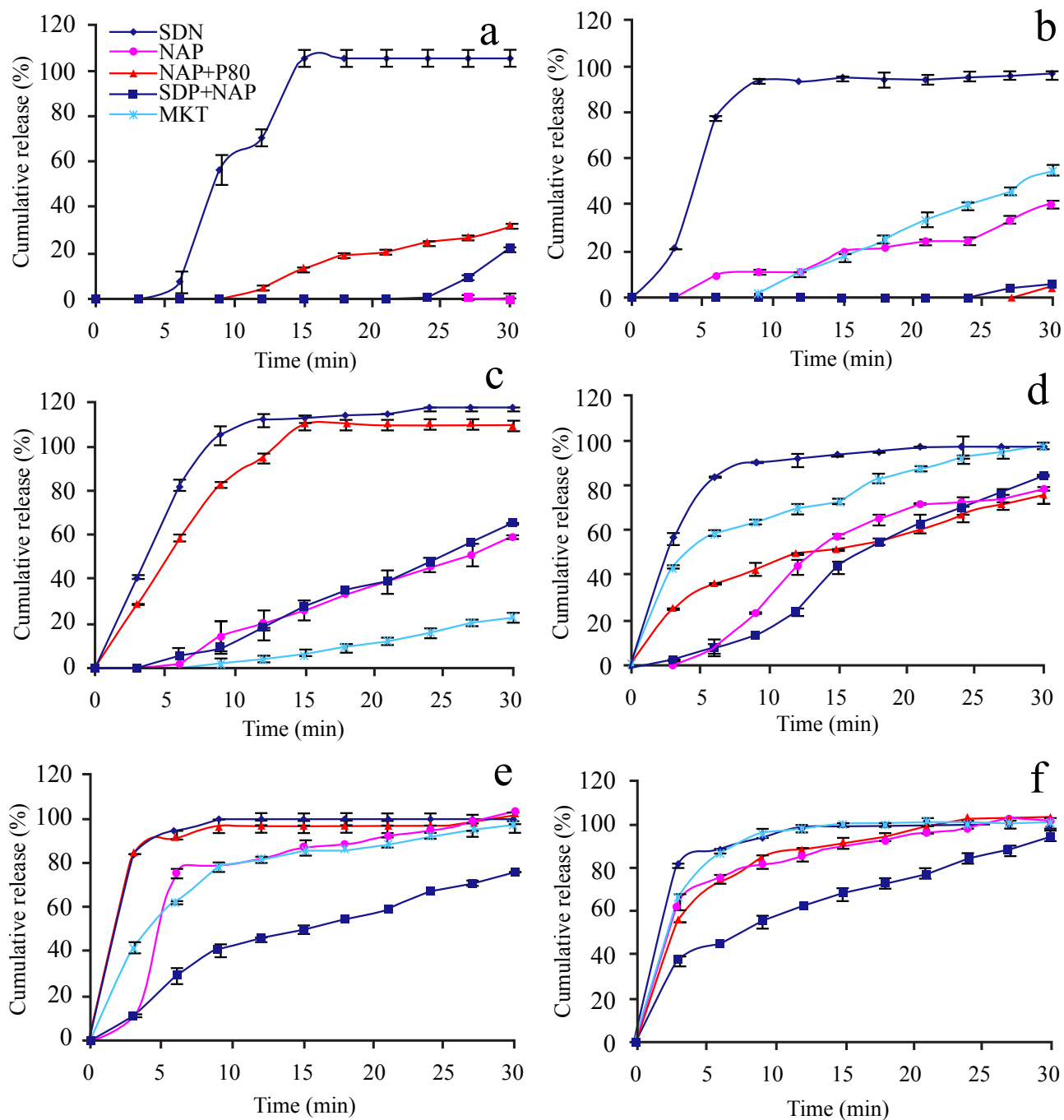

Notes: Each point represents the mean $\pm \mathrm{SD},(\mathrm{n}=3)$; :Spray-dried naproxen $(\mathrm{SDN})$; Pure naproxen (NAP); Spray-dried placebo and naproxen (SDP+NAP); Naproxen with equivalent amount of surfactant in the dissolution medium (NAP+T80); and Naprosyn® (MKT)

Figure 6: Cumulative release profiles of naproxen from powder in: (a) $0.1 \mathrm{~N} \mathrm{HCl}$, (b) pH 4.5 acetate buffer, (c) $\mathrm{DM}$ water and (d) pH 6.0 phosphate buffer, (e) pH 6.8 phosphate buffer, (f) $0.1 \mathrm{M} \mathrm{pH} 7.4$ phosphate.

\begin{tabular}{|c|c|c|}
\hline Ingredients & \multicolumn{2}{|c|}{ Amount per tablet in formulation (mg) } \\
\hline & SDN+SDL & \multicolumn{2}{|c|}{ SDP+SDL+NAP } \\
\hline Spray-dried naproxen* & $319.48^{*}$ & 0.00 \\
\hline Spray-dried placebo & 0.00 & 313.96 \\
\hline Naproxen & 0.00 & 5.00 \\
\hline Spray-dried lactose (SDL as diluent) & 52.33 & 5.00 \\
\hline Magnesium stearate & 1.86 & 5.00 \\
\hline Total & 373.67 & 3.85 \\
\hline
\end{tabular}

Note: ${ }^{*} 319.48 \mathrm{mg}$ of SDN contains $5 \mathrm{mg}$ of naproxen.

Table 6: Composition of tablets.

concentration reaches $\mathrm{cmc}$, the solubility increases linearly attributing to the fact that solubilization is related to micellization. This linear increment is due to the increase in the size and number of micelles.

A linear relation between drug solubility and surfactant concentration is evident in the form of following equation.

$$
\chi=\left(\mathrm{S}_{\text {tot }}-\mathrm{S}_{\mathrm{w}}\right) /\left(\mathrm{C}_{\text {surf }}-\mathrm{cmc}\right)
$$

Where $S_{\text {tot }}$ is the total drug solubility, $S_{w}$ is the drug solubility in water, $\mathrm{C}_{\text {surf }}$ is the molar concentration of surfactant in solution, ' $\mathrm{cmc}$ is the critical micelle concentration and the term ' $\chi$ ' is solubilization capacity. In accordance with the above equation, several earlier researchers found linearity between drug solubility and surfactant concentration $[38,39,44,45]$. The post micellar concentration of surfactants employed by earlier workers was smaller than that usually 
Citation: Maheswari PD, Rambhau D, Narasu ML (2013) Micellar Solubilization in the Formulation Development of Poorly Soluble Naproxen. Pharmaceut Reg Affairs 2: 108. doi:10.4172/2167-7689.1000108

Page 9 of 12

\begin{tabular}{|c|c|c|c|c|c|c|}
\hline Formulation code & $W V^{*}(g)$ & Thickness* $^{*}(\mathrm{~mm})$ & Friability* $(\%)$ & Hardness $\left(\mathrm{Kg} / \mathrm{cm}^{2}\right)^{\star *}$ & $\begin{array}{l}\text { CU } \\
(\%)^{* *}\end{array}$ & $\begin{array}{c}\text { DT } \\
(\min )^{* * *}\end{array}$ \\
\hline SDN+SDL & $0.38 \pm 3.52$ & $3.56 \pm 0.09$ & $0.39 \pm 0.01$ & $3.66 \pm 0.46$ & $101.25 \pm 1.78$ & $24.26 \pm 2.14$ \\
\hline $\mathrm{SDP}+\mathrm{SDL}+\mathrm{NAP}$ & $0.39 \pm 5.63$ & $3.77 \pm 0.20$ & $0.27 \pm 0.003$ & $3.56 \pm 0.17$ & $100.83 \pm 1.63$ & $20.24 \pm 1.51$ \\
\hline SDL+NAP & $0.38 \pm 13.28$ & $3.29 \pm 0.12$ & $0.31 \pm 0.004$ & $4.72 \pm 0.17$ & $98.13 \pm 1.65$ & $6.15 \pm 1.28$ \\
\hline
\end{tabular}

Note: Each point represents mean \pm SD $\left({ }^{*} n=20 ;{ }^{* *} n=10,{ }^{* * *} n=6\right)$; WV: Weight Variation; CU: Content Uniformity; DT: Disintegration Time.

Table 7: Evaluation parameters of naproxen tablets, $5 \mathrm{mg}$.
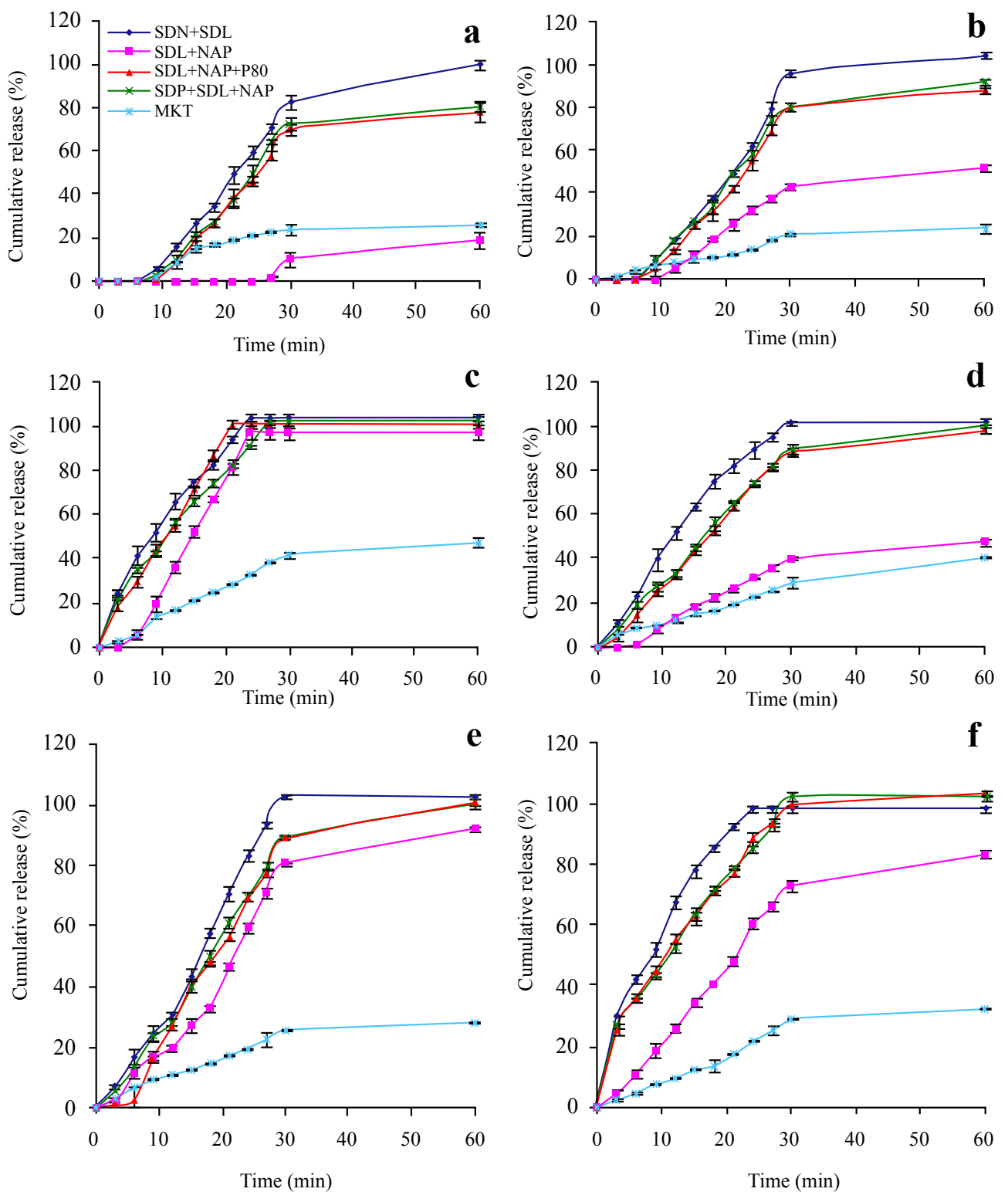

Notes: Each point represents the mean \pm SD, $(n=3)$. *Tablets made with spray-dried naproxen and Spray-dried lactose (SDN+SDL); Spray-dried lactose and naproxen (SDL+NAP); Spray-dried placebo, Spray-dried lactose and naproxen (SDP+SDL+ NAP); Spray-dried lactose and naproxen with equivalent amount of surfactant in the dissolution medium (SDL+NAP+T80); and Naprosyn® (MKT).

Figure 7: Cumulative release profiles of naproxen from tablets ${ }^{*}$ in: (a) $0.1 \mathrm{~N} \mathrm{HCl}$, (b) pH 4.5 acetate buffer, (c) $\mathrm{DM}$ water and (d) pH 6.0 phosphate buffer, (e) pH 6.8 phosphate buffer, and (f) $0.1 \mathrm{M} \mathrm{pH} 7.4$ phosphate.

employed in pharmaceutical formulation, particularly to solubilize the drugs in aqueous solutions. Many drug formulations require more than $10 \%$ surfactant concentration and as high as $25 \%$ are employed to resolve solubility issues. To solubilize NAP in water, we have employed a post micellar surfactant concentration ranging from $1 \%$ to $25 \%$ (Table 9). In this broad range, linearity between solubility and surfactant concentration was found between $1 \%(10 \mathrm{mg} / \mathrm{mL})$ to $5 \%(50$ $\mathrm{mg} / \mathrm{mL}$ ), beyond which linearity suffered.

Rangel-Yagui et al. evaluated solubilization of a drug molecule in context to the solubilization capacity, $\boldsymbol{\chi}$ and micellar water partition 
Citation: Maheswari PD, Rambhau D, Narasu ML (2013) Micellar Solubilization in the Formulation Development of Poorly Soluble Naproxen. Pharmaceut Reg Affairs 2: 108. doi:10.4172/2167-7689.1000108

Page 10 of 12

\begin{tabular}{|c|c|c|c|c|c|}
\hline \multirow[t]{3}{*}{ Formulations } & \multicolumn{5}{|c|}{ Storage time (months) } \\
\hline & & \multicolumn{2}{|c|}{$25 \pm 2^{\circ} \mathrm{C} / 60 \pm 5 \% \mathrm{RH}$} & \multicolumn{2}{|c|}{$40 \pm 2^{\circ} \mathrm{C} / 75 \pm 5 \% \mathrm{RH}$} \\
\hline & 0 & 3 & 6 & 3 & 6 \\
\hline \multicolumn{6}{|l|}{ Drug content $(\% \mathrm{w} / \mathrm{w})$} \\
\hline SDN powder & $91.01 \pm 3.37$ & $96.30 \pm 2.47$ & $98.77 \pm 0.0$ & $99.18 \pm 1.43$ & $98.77 \pm 0.00$ \\
\hline SDN+SDL tablets & $99.59 \pm 3.77$ & $97.94 \pm 1.89$ & $95.06 \pm 0.00$ & $97.53 \pm 3.27$ & $101.23 \pm 1.23$ \\
\hline \multicolumn{6}{|c|}{ Moisture content $(\%$ w/w) } \\
\hline SDN powder & $1.55 \pm 0.02$ & $1.71 \pm 0.03$ & $1.57 \pm 0.16$ & $1.60 \pm 0.03$ & $1.74 \pm 0.03$ \\
\hline SDN+SDL tablets & $1.67 \pm 0.04$ & $2.03 \pm 0.12$ & $1.90 \pm 0.11$ & $1.84 \pm 0.04$ & $2.01 \pm 0.13$ \\
\hline
\end{tabular}

Note: Each point represents mean \pm SD $(n=3)$.

Table 8: Stability study of optimized batches upon storage at $25 \pm 2^{\circ} \mathrm{C} / 60 \pm 5 \% \mathrm{RH}$ and $40 \pm 2{ }^{\circ} \mathrm{C} / 75 \pm 5 \% \mathrm{RH}$

\begin{tabular}{|c|c|c|c|c|c|c|c|c|}
\hline \multirow[b]{2}{*}{ Code } & \multirow[b]{2}{*}{$\begin{array}{c}\text { Surfactant } \\
(\% \mathrm{w} / \mathrm{v})\end{array}$} & \multirow[b]{2}{*}{ cmc (mM) } & \multicolumn{3}{|c|}{ RT } & \multicolumn{3}{|c|}{ СРT } \\
\hline & & & $X(m M)$ & $P_{M}$ & $\begin{array}{c}\Delta \mathrm{G}_{\mathrm{s}}{ }^{0} \\
(\mathrm{~kJ} / \mathrm{mol})\end{array}$ & $\begin{array}{c}X \\
(\mathrm{mM})\end{array}$ & $P_{M}$ & $\begin{array}{c}\Delta \mathrm{G}_{\mathrm{s}}{ }^{0} \\
(\mathrm{~kJ} / \mathrm{mol})\end{array}$ \\
\hline \multirow[t]{4}{*}{ P20 } & 1 & \multirow{4}{*}{0.05} & 102.0 & 378.7 & -3.0 & 182.3 & 505.7 & -4.6 \\
\hline & 5 & & 62.7 & 232.7 & -5.8 & 102.4 & 284.1 & -7.8 \\
\hline & 15 & & 105.9 & 393.2 & -9.8 & 155.3 & 430.9 & -12.5 \\
\hline & 25 & & 210.9 & 783.0 & -12.8 & 217.2 & 602.7 & -15.0 \\
\hline \multirow[t]{4}{*}{ P80 } & 1 & \multirow{4}{*}{0.01} & 320.7 & 1190.9 & -5.5 & 368.0 & 1020.8 & -6.2 \\
\hline & 5 & & 287.8 & 1068.8 & -9.2 & 294.4 & 816.8 & -10.4 \\
\hline & 15 & & 335.5 & 1246.0 & -12.3 & 335.9 & 931.8 & -13.9 \\
\hline & 25 & & 277.4 & 1029.9 & -13.1 & 311.8 & 865.0 & -15.2 \\
\hline \multirow[t]{4}{*}{$\mathrm{CRH} 40$} & 1 & \multirow{4}{*}{0.10} & 387.7 & 1439.7 & -4.1 & 497.3 & 1379.6 & -4.9 \\
\hline & 5 & & 235.4 & 874.0 & -6.9 & 278.3 & 771.9 & -8.0 \\
\hline & 15 & & 277.3 & 1029.5 & -10.0 & 393.2 & 1090.8 & -12.4 \\
\hline & 25 & & 301.0 & 1117.7 & -11.5 & 352.6 & 978.0 & -13.6 \\
\hline \multirow[t]{4}{*}{ ST15 } & 1 & \multirow{3}{*}{0.21} & 0.9 & 3.4 & 5.8 & 51.1 & 141.7 & -4.1 \\
\hline & 5 & & 3.6 & 13.4 & -1.6 & 18.1 & 50.2 & -5.8 \\
\hline & 15 & & 9.1 & 33.6 & -6.6 & 10.3 & 28.7 & -7.3 \\
\hline & 25 & & 6.3 & 23.5 & -7.0 & 8.6 & 23.9 & -8.2 \\
\hline
\end{tabular}

Notes: RT, room temperature; CPT, cloud point temperature; $\mathrm{P}_{\mathrm{w}}$, Micelle water partition co-efficient.

$X$ has been expressed as millimoles of drug solubilized per mol surfactant and $\Delta \mathrm{G}_{\mathrm{s}}{ }^{0}$ values are in kilojoules per mole at $298 \mathrm{~K}$ at $\mathrm{RT}$. and CPT.

Table 9: Solubilization parameters from naproxen solubility study by micellar solubilization.

coefficient, P [44]. P indicates affinity of a drug molecule towards micelle and thus higher the $\mathrm{P}$-value higher is the drug-micelle interaction and higher is the solubility.

The effective partition of drug molecules towards micelle is the primary step in the process of micellar solubilization. At high surfactant concentrations owing to the higher size and number of micelles in a limited aqueous space, aggregation of micelles might occur as a result of crowding via dipole and/or hydrophobic interactions. This should negatively influence the micelle-water partition, thereby limiting the micellar solubilization capacity. We presume some such unfavorable conditions exist for partitioning of NAP molecules towards micelle resulting in ineffective micellar solubilization of NAP at higher concentrations.

Normally, higher the temperature higher is the micellar solubilization [45]. In general the increase in solubility of NAP was observed at $\mathrm{CPT}$ over the RT. However, at CPT there is a substantial improvement in solubility of NAP only at lower surfactant concentrations (Figure 1). We therefore believe that due to combined effect of higher surfactant concentration and temperature (at CPT) the affinity of NAP towards micelle drastically reduces because of crowding and hydrophobization of micelles respectively, thereby resulting in poor solubilization. This phenomenon at CPT was consistent in all surfactants employed. However, some variability in percent solubility improvement at CPT versus surfactant concentration plots (Figure 1) is obviously due to the nature of surfactants and their physicochemical characteristics; particularly their $\mathrm{cmc}$ and water solubility.

Too much significant values of Gibbs free energy in Table 9 are because of the non ideal (non linear) behavior of ' $\chi$ ' with high surfactant concentrations employed in this study. The reasons for such a behavior are explained above. The increase in negativity of $\Delta \mathrm{G}_{\mathrm{s}}{ }^{0}(\mathrm{~kJ} / \mathrm{mol})$ value with the increase in concentration of the surfactant, reveals substantial enhancement of solubility of NAP.

\section{Conclusion}

The aqueous solubility of naproxen was successfully improved by micellar solubilization technology employing CPT as the tool for solubilization of drug. A combination of micellar solubilization and cloud point temperature of the surfactants could be used effectively to enhance the dissolution of a poorly water-soluble drug like naproxen. Spray drying has resulted in the conversion of the micellar solution into good flowable powders with reasonable compressibility properties. Spray drying resulted in nearly spherical microparticles of lactose, in which micelles containing NAP were entrapped. Micellar solubilization is a novel method of incorporating surfactants into tablets with a much 
Citation: Maheswari PD, Rambhau D, Narasu ML (2013) Micellar Solubilization in the Formulation Development of Poorly Soluble Naproxen. Pharmaceut Reg Affairs 2: 108. doi:10.4172/2167-7689.1000108

improved performance of surfactants. Thus, during the process of dissolution of SDN and SDN+SDL tablets the structure of micelle is unaltered even in presence of variety of dissolution media with differing $\mathrm{pH}$ conditions ( $\mathrm{pH} 1.2$ to $\mathrm{pH}$ 7.4). Spray-dried naproxen powder and tablets made out of it were stable under accelerated stability test and no substantial change was observed.

\section{Acknowledgment}

The authors would like to thank Mr. Nannapaneni Venkaiah Chowdary, Chairman cum Managing Director, Natco Pharma Limited, Hyderabad, India for permitting the research work and utilizing the full-fledged facility.

\section{Declaration of Interest}

The authors report no conflicts of interest. The authors alone are responsible for the content and writing of this article.

\section{References}

1. Lipinski CA, Lombardo F, Dominy BW, Feeney PJ (2001) Experimental and computational approaches to estimate solubility and permeability in drug discovery and development settings. Adv Drug Deliv Rev 46: 3-26.

2. Loftsson T, Brewster ME, Masson M (2004) Role of cyclodextrins in improving oral drug delivery. American Journal of Drug Delivery 2: 261-275.

3. Banerjee R, Chakraborty H, Sarkar M (2004) Host-guest complexation of oxicam NSAIDs with beta-cyclodextrin. Biopolymers 75: 355-365.

4. Gupta U, Agashe HB, Asthana A, Jain NK (2006) Dendrimers: novel polymeric nanoarchitectures for solubility enhancement. Biomacromolecules 7: 649-658.

5. Dixit AR, Rajput SJ, Patel SG (2010) Preparation and bioavailability assessment of SMEDDS containing valsartan. AAPS PharmSciTech 11: 314-21.

6. Bastin RJ, Bowker MJ, Slater BJ (2000) Salt selection and optimisation procedures for pharmaceutical new chemical entities. Org Proc Res Dev 4: 427-435

7. Rong Liu (2008) Water insoluble drug formulation. (2ndedn) CRC Press, Taylor \& Francis Group, USA. 133-467.

8. Sinko PJ (2009) Martin's Physical Pharmacy and Pharmaceutical Sciences. Lipincott Williams \& Wilkins, USA.

9. Haque T, Talukder MU, Laila S, Fatema K, Islam MS, et al. (2009) Mode Dependent and Independent Approaches to Compare In vitro Release Profiles from Ethylcellulose and Eudragit L100 Based Matrix Tablets. Dhaka Univ J Pharm Sci 8: 89-98.

10. Ritu Priya M, Maheshwari RK, Mahajan SC (2010) Spectrophotometric estimation of naproxen using N,N-dimethyl urea as hydrotropic agent. The Indian pharmacist 9: 67-69.

11. Maheshwari RK, Indurkhya A, Jawade S, Jagwani Y (2009) Spectrophotometric estimation of naproxen tablets employing sodium benzoate as hydrotropic additive. The Indian pharmacist 8: 75-77.

12. Maheshwari RK, Dubey A (2008) Quantitative estimation of naproxen in bulk sample and tablet formulation using niacinamide as hydrotropic solubilizing agent. Asian Journal of Chemistry 20: 4225-4228.

13. Maheshwari RK, Wanare G, Chahar N, Joshi P, Nayak N (2009) Quantitative estimation of naproxen in tablets using Ibuprofen sodium as hydrotropic agent. Indian J Pharm Sci 71: 335-337.

14. William BH, Donna MM, Mueller Ronald L, Swanson, Jon R, et al. (1996) Process for preparing therapeutic compositions containing nanoparticles. US $5510118 \mathrm{~A}$.

15. Arlie BB (1999) Patent: Solubilizing delivery systems and method of manufacture. Canada Patent CA 2247994.

16. Kim Jae-Hwan, Lee Kyung-Sik, Shin Woo-Choul, Lee So-Ra, Yi Jae-Hun (2004) Solvent system of hardly soluble drug with improved dissolution rate. US20040157928 A1.

17. Chen Feng-jing, Patel Manesh V (2000) Compositions and methods for improved delivery of ionizable hydrophobic therapeutic agents. WO 2000059475 A1

18. Wang M, Jian-Wei Y, Ying W, Jian-De L, Xiao-Yun F (2003) Effect of micellar solution systems on acidic compound separation by electrokinetic chromatography. Huaxue xuebao 61: 1980-1985.
19. Paudel A, Van Humbeeck J, Van den Mooter G (2010) Theoretical and experimental investigation on the solid solubility and miscibility of naproxen in poly(vinylpyrrolidone). Mol Pharm 7: 1133-1148.

20. Tiong N, Elkordy AA (2009) Effects of liquisolid formulations on dissolution of naproxen. Eur J Pharm Biopharm 73: 373-384.

21. Chen Yuan-Yuan, Liu Jia-Jia, Tang Ke-Wen, Zhang Guo-Li (2007) Evaluation of HP- $\beta-C D$ as solubilizing/stabilizing agent for naproxen. Guangpu Shiyansh 24: $632-636$.

22. Zhan Guo-ping, Pan Dao-li (2007) Preparation of naproxen- $\beta$-cyclodextrin inclusion complex. Hecheng Huaxue 15: 65-68.

23. Wongmekiat A, Yoshimatsu S, Tozuka Y, Moribe K, Yamamoto K (2006) Investigation of drug nanoparticle formation by co-grinding with cyclodextrins: studies for indomethacin, furosemide and naproxen. Journal of inclusion phenomena and macrocyclic chemistry 56: 29-32.

24. Cirri M, Maestrelli F, Corti G, Furlanetto S, Mura P (2006) Simultaneous effect of cyclodextrin complexation, $\mathrm{pH}$, and hydrophilic polymers on naproxen solubilization. J Pharm Biomed Anal 42: 126-131.

25. Mura P, Maestrelli F, Cirri M (2003) Ternary systems of naproxen with hydroxypropyl-beta-cyclodextrin and aminoacids. Int J Pharm 260: 293-302.

26. Vélaz I, Sánchez M, Martín C, Martínez-Ohárriz MC (1998) Effect of PEG 4000 on the dissolution rate of naproxen. Eur J Drug Metab Pharmacokinet 23: $103-108$.

27. Mura P, Manderioli A, Bramanti G, Ceccarelli L (1996) Properties of solid dispersions of naproxen in various polyethylene glycols. Drug Development and Industrial Pharmacy 22: 909-916.

28. Lee BJ, Lee JR (1995) Enhancement of solubility and dissolution rate of poorly water-soluble naproxen by complexation with 2-hydroxypropyl- $\beta$-cyclodextrin Archives of Pharmacal Research 18: 22-26.

29. Bettinetti G, Mura P (1994) Dissolution properties of naproxen in combinations with polyvinylpyrrolidone. Drug Development and Industrial Pharmacy 20: 1353-1366.

30. Bettinetti G, Gazzaniga A, Mura P, Giordano F, Setti M (1992) Therma behaviour and dissolution properties of naproxen in combinations with chemically modified ß-Cyclodextrins. Drug Development and Industrial Pharmacy 18: 39-53

31. Celebi N, Erden N (1992) Interaction of naproxen with $\beta$-cyclodextrin in ground mixture. International Journal of Pharmaceutics 78: 183-187

32. Bettinetti GP, Mura P, Liguori A, Bramanti G, Giordano F (1988) Solubilization and interaction of naproxen with polyvinylpyrrolidone in aqueous solution and in the solid state. Farmaco Prat 43: 331-343.

33. Nurham E, Nevin C (1988) The effect of $\beta$-cyclodextrin on solubility and dissolution rate of naproxen. Fac. Pharm., Gazi Univ., Ankara, Turk. Gazi Universitesi Eczacilik Fakultesi Dergisi 5: 91-99.

34. Yiyun C, Jiepin Y (2006) Solubilization of non-steroidal anti-inflammatory drugs in the presence of tween series surfactants. Physics and Chemistry of Liquids 44: $249-256$

35. Mura P, Faucci MT, Manderioli A Bramanti G, Parrini P (1999) Therma behavior and dissolution properties of naproxen from binary and ternary solid dispersions. Drug Dev Ind Pharm 25: 257-264.

36. Moore JW, Flanner HH (1996) Mathematical comparison of dissolution profiles. Pharmaceutical Technology 20: 64-74.

37. Guidance for Industry Q1A(R2) Stability Testing of New Drug Substances and Products (2003) U.S. Department of Health and Human Services, Food and Drug Administration.

38. Wong SM, Kellaway IW, Murdan S (2006) Enhancement of the dissolution rate and oral absorption of a poorly water soluble drug by formation of surfactantcontaining microparticles. Int J Pharm 317: 61-68.

39. Wikarsa S, Durand D, Delarbre JL, Baylac G, Bataille B (2008) The improvement of ibuprofen dissolution rate through microparticles spray drying processed in an aqueous system. Drug Dev Ind Pharm 34: 485-491.

40. Alanazi FK, El-Badry M, Ahmed MO, Alsarra IA (2007) Improvement of Albendazole dissolution by preparing microparticles using spray-drying technique. Scientia Pharmaceutica (Sci Pharm) 75: 63-79.

41. Sahoo NG, Kakran M, Li L, Judeh Z (2010) Fabrication of composite 
Citation: Maheswari PD, Rambhau D, Narasu ML (2013) Micellar Solubilization in the Formulation Development of Poorly Soluble Naproxen. Pharmaceut Reg Affairs 2: 108. doi:10.4172/2167-7689.1000108

microparticles of artemisinin for dissolution enhancement. Powder Technology 203: $277-287$.

42. de Souza MC, Marchetti JM (2012) Development of albendazole sulfoxideloaded Eudragit microparticles: A potential strategy to improve the drug bioavailability. Advanced Powder Technology 23: 801-807.

43. Maghsoodi M (2009) Physicomechanical properties of naproxen-loaded microparticles prepared from Eudragit I100. AAPS PharmSciTech 10: 120-128.
44. Rangel-Yagui CO, Pesoa Jr A, Tavares LC (2005) Micellar solubilization of drugs. J Pharm Pharmaceut Sci 8: 147-163.

45. Park YJ, Lee HK, Im YB, Lee W, Han HK (2010) Improved pH-Independent dissolution and oral absorption of valsartan via the preparation of solid dispersion. Arch Pharm Res 33: 1235-1240. 